\title{
8
}

\section{TOWARDS DESIGN PRINCIPLES FOR DIVERSITY SENSITIVE LEARNING}

\author{
Rico Lie, Birgit K. Boogaard, and Loes Witteveen
}

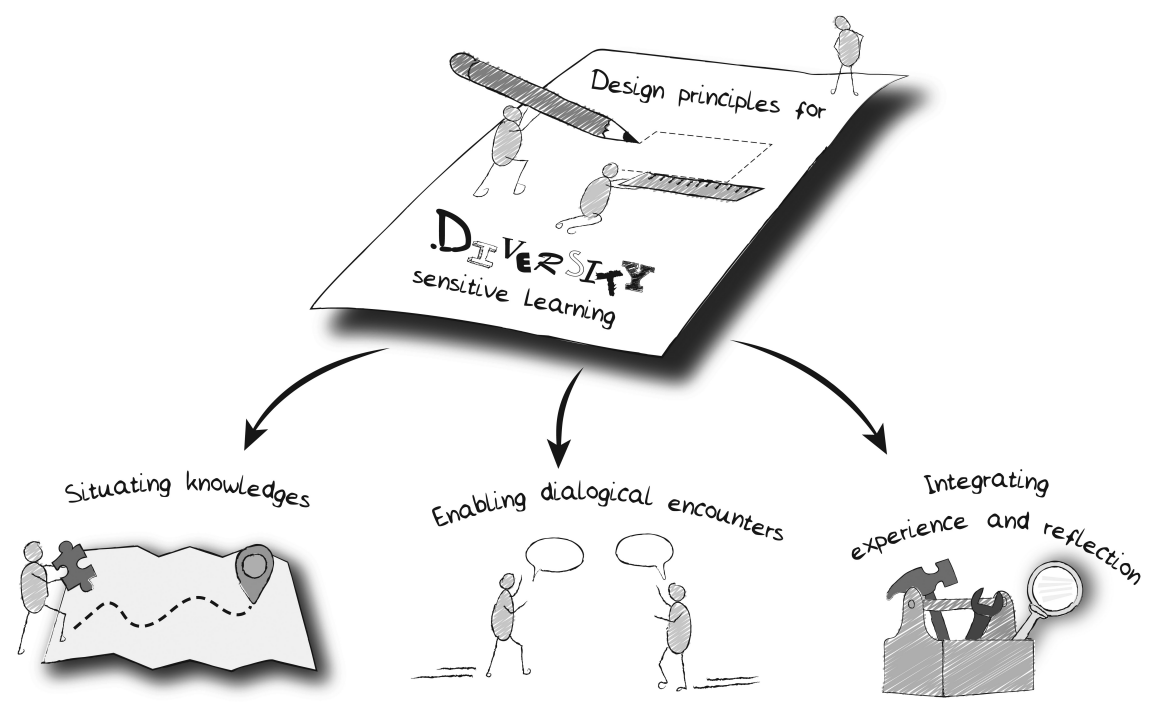

\section{Introduction}

With the increasing recognition of science and society interfaces in times of the Anthropocene and with complex sustainability challenges, authors like Scholz and Steiner (2015) and Gilbert (2016) have explored transforming the role of research and education. Such a societal perspective proposes an alignment of Higher Education policies and practices with contemporary issues. A changing world order and the recent attention to Black Lives Matter (BLM) protests added even more urgency to the perspective of diversity sensitive learning addressed in 
this chapter. Diversity is increasingly seen as a factor that needs to be considered to make knowledge work in our current educational systems and beyond; in a globalised world (university) cultures become increasingly heterogeneous, with students and teachers originating from and working in international and culturally diverse contexts. Considering Higher Education as an imperative place where knowledge is (re)produced, based on ontological assumptions of objectivity and normative truths, the chapter explores design principles for diversity sensitive learning in a Netherlands university setting.

In August 2020, the Ministry of Education, Culture and Science in the Netherlands launched the National Action Plan for Greater Diversity and Inclusion in Higher Education and Research. This action plan sets various goals for Higher Education and Research for 2025 to achieve 'an inclusive, diverse and safe learning and working environment in which everyone has the opportunity to flourish' (Ministry of Education, Culture and Science in the Netherlands, 2020 , p. 5). Through the implementation of the action plan, the Ministry aims 'to increase diversity both among students and staff and in research and educational content' (ibid, p. 9).

This increase in diversity is needed to align with societal developments and especially fits the perspective of Wageningen University and its slogan: 'Quality needs diversity' (WUR, 2020). Wageningen University explicitly states in the document that the university values diversity and, to implement this, it adheres to four principles when it comes to working in multicultural settings: (1) empathy; (2) respect for each other; (3) scope for authenticity; and (4) communication and, in particular, listening carefully (WUR, 2020). Its scope nevertheless falls short on the recognition of systemic problems, and so it neglects the content focus and learning strategies which are implicitly being favoured.

Taking the above critique into account while considering societal processes of globalisation and localisation, this chapter addresses diversity by focussing on what we have termed 'diversity sensitive learning.' The chapter has a focus on learning designs in formal Higher Education and aims to identify (foundational) design principles for such diversity sensitive learning. The assumption is that in making these principles explicit, they become accessible and can enhance the quality of learning designs. As an illustration, this chapter probes three courses offered by the Social Sciences Department at Wageningen University. The chapter envisions through an empirical approach to formulate design principles that can be useful for courses offered by the Social Sciences Department of Wageningen University and beyond.

\section{An empirical approach to explore learning spaces for diversity}

The empirical foundation for this chapter is the analysis of three specific courses: Intercultural Communication (CPT-35806 by Rico Lie), African 
Philosophy (CPT-58306 by Birgit Boogaard), and Visual Research Methods (CPT-58802 by Loes Witteveen). Three reasons underlie the choice of these courses. First, the authors of this chapter were the main actors involved in the design and teaching of these courses. The second is the diverse scientific groundings of the three courses: Intercultural Communication is grounded in communication science, intercultural and cross-cultural communication, social anthropology, and cultural studies; African Philosophy follows an intercultural philosophical approach; and Visual Research Methods, as a methodology course, is founded on methodology studies combined with sociology, cultural studies, and media studies. Finally, all three courses embark on aspects of diversity sensitive learning in relation to (cultural) content, and they address the relationship between content matters and cultures in various ways. In all three courses, learning from diversity refers to processes and outcomes to enhance the quality of learning. These three reasons enhance the presence and visibility of design principles.

The chapter does not detail the learning goals and setup of each course. Instead, it exemplifies diversity sensitive learning in a reflective and open, explorative way, highlighting several features of the courses which contribute to 'diversity sensitive learning.' In each feature-i.e. each sub-heading-it is first explained why a particular learning strategy is included in the course and subsequently how it is applied in the course. The next section presents the three courses; we then describe the underlying principles which emerged from comparing and analysing the features that address diversity sensitive learning in each course.

\section{Intercultural Communication}

\section{Know the knowledge that already exists}

The course used the knowledge that people already acquired through earlier experiences (experiential learning) and combined this with learning new knowledge produced by others. The course focused on theories of globalisation, theories about cultural mixing, theories about acculturation, and identity construction, with the students learning about the differences between stereotypes and prejudices.

In the course, we shared Joyce Osland's acculturation theory based on Joseph Campell's work on mythic heroes in which the ex-pat (the hero) travels a sixpart journey: (1) the call to adventure; (2) the belly of the whale (being in an unknown culture); (3) the magical friend (a cultural mentor); (4) the road of trials (paradoxes); (5) the ultimate boon (the transformation of self); and (6) the return (things have changed) (Osland, 1995). Students recognised the parts of the journey, felt that they shared that in the group and that they do have similar experiences. Having this shared frame of knowledge enabled students to project their own experiences. 


\section{Intersubjectivity}

Objectivity does not exist. All actions and all learnings are biased, and a first step in realising this is making biases as explicit as possible. However, this epistemological positioning does not mean that there is no value in subjectivity. We can share and agree on the kind of subjectivity and the content of subjectivity. Intersubjectivity is agreeing with different subjects that a particular interpretation is valid, makes sense, or is even true.

In the 'Museum Assignment' called Representing the Other, students visited an ethnographic museum in groups and conducted semiotic analyses of 'the Other.' Students selected an ethnographic museum and an object (statue, painting, photograph) or a specific exhibition within the museum. The groups in which they conducted the assignment were formed by the teacher based on diversity in (1) nationality, (2) study programme, and (3) gender. This diversity leads to discussions in the group about interpretations, and it was especially these discussions that should somehow be written down and reflected upon in the student report.

\section{Sensitivity}

This aspect addresses how to become sensitive to differences, without knowing the exact form of the differences. As with the previous two aspects, becoming sensitive requires making things explicit.

Sensitivity was trained in role play through analysing films and by applying theories from the field of intercultural communication to one's interests and/or experiences in an essay. In the essay assignment, students were asked to select a specific intercultural experience that they had, that confused them, or that in another way made an impression. Alternatively, they could choose a popular text. Once they made their choice, they then analysed that situation (or popular text) through applying compulsory literature analyses, which included one peerreviewed academic article of their own choosing. In this way, they became sensitive through reinterpretation, using different (academic) perspectives.

\section{African Philosophy}

\section{Learning about and from a diversity of knowledge}

The historical exclusion and systematic suppression of African philosophy in academic curricula maintains and reinforces epistemic injustice (Boogaard, 2019; Ramose, 2019). The need for epistemological diversity in academic curricula is in line with a wider call for 'mental decolonisation' and 'decolonising universities' (Bhambra et al., 2018). In this course, students therefore learned about African philosophies, such as Henry Odera Oruka's (1995) sage philosophy and Ubuntu philosophy (Ramose, 1999).

Students read texts written by African philosophers and watched videos with interviews of African philosophers. This is crucial: hearing perspectives 
and reasoning from African philosophers themselves; and not just by talking about people or their knowledges. Students highly appreciated the content of the course, as it provided perspectives that they hardly ever encountered in their regular study program.

\section{Eurocentrism and self-reflectivity}

Many students from Wageningen University will work in international and culturally diverse contexts and desire to affect social change across the globe. Especially for those students, it is important to critically reflect on their views and assumptions about Africa, which often tend to be Eurocentric. African philosophy demands that we critically reflect on Eurocentric ways of perceiving and reasoning about the world (Kimmerle, 2016).

By reading and discussing Hegel's Eurocentric concept of philosophy (Kimmerle, 2016), students learned that Africans had historically been portrayed as 'the Other' who do not have a philosophy. In addition, the teacher and students jointly reflected how Eurocentrism continues to exist until today, particularly in international development in Africa. This was done via storytelling, where the teacher told her experiences in a research for development project in Mozambique (Boogaard, forthcoming). Students answered the question 'In what ways was my [the teacher's] thinking Eurocentric?' The power of this exercise lies in the combination of the content, people, and process: diversity sensitive learning is not only about 'other' people far away (Mozambican goat keepers), but even more so about ourselves (the Western-trained researcher). By jointly reflecting on how the teacher's thinking was Eurocentric, the process provided a safe learning environment, which is a prerequisite for truthful—and sometimes confronting-self-reflectivity.

\section{Methodology of listening}

General academic skills tend to focus on debating, in which one aims to convince another of a particular viewpoint. However, culturally sensitive learning requires dialogical encounters, in which one tries to understand a different way of reasoning and different kinds of knowledges apart from one's own. As such, intercultural dialogues can lead to mutual understanding between dialogue partners. To be able to engage in mutually respectful intercultural dialogues, we need to first listen; not in terms of 'good' or 'bad,' but in terms of being different from each other and with a willingness to learn from others (Kimmerle, 2012).

Students conducted empathic interviews with fellow students in pairs. They talked about their (future) study and work ambition, particularly in relation to Africa. The key point was that they practised listening to each other without providing their own experiences and judgments. Subsequently, students switched roles so that each student practised with the methodology of listening. 


\section{Visual Research Methods (VRM)}

\section{Portrayal of diversity in society}

For students to gain insight on the dynamic continuum of semiotic and sociocultural constructionist approaches, De Saussure's models of sign and language systems, a Foucauldian perspective on the socio-cultural and political context of media industries, and a model of 'sites and modalities for interpreting visual materials' (Rose, 2016) are theorised and practised.

Students analysed the portrayal of diversity in Dutch society with the covers of the ninth volume (22 covers, A4) of the Wageningen University and Research (WUR) magazine Resource and an underwear brochure by retailer Zeeman (33 pages, A5). The analysis of Resource covers illustrated how diversity of ethnicity and gender is hardly observable: one lady with a veil is seen in the background, but overall women's visibility is limited; meanwhile, white men are portrayed as travelling, doing hard science, and as decision-makers. Findings for the Zeemancampaign showed diversity expressed for socio-economic categories with the inclusion of outdoor workers, a grandmother, and diverse representations of ethnicity, age, gender, and body shape. Students hesitantly concluded that the retailer 'represents diversity in the Netherlands, even more when compared to the WUR magazine.' It was also resolved that 'Resource covers portray the WUR community in a patriarchal style, in a very Dutch and "tongue in cheek" way,' and that 'If the content analysis of the covers of Resource would indicate diversity in practice at WUR, it gives a bleak picture' (VRM student reports).

\section{Reversal of representation and orientalism}

Following Stuart Hall's terminology, all media materials are 'encoded,' but visuals are often read while taking the coding for granted (Hall, Evans, and Nixon, 2013; also Witteveen and Lie, 2019). Through reversal and a focus on production, students gain sensitivity to systemic processes of symbolic meaning creation.

Students explored the production of 'Updating Cocoa Stories' (Witteveen and Van, Rijn, 2014) a short film presented by the Dutch Minister for Agriculture during her opening speech at the World Cocoa Conference on 10 June 2014. The initial script for the film summarised a 1952 film. A group of Ghanaian WUR students rejected the outdated and colonial representation of Ghana and proposed another script, which was accepted for production by the Dutch commissioning ministry. Exploring the production unveils continuity of 'orientalism' and 'othering,' even when unintentional.

\section{Continuous reflection on learning}

To support a continuous process of reflection on one's biases concerning processes of encoding and decoding, a wide array of diverse portrayal and visual 
discourses are enacted in all course materials, including interwoven 'making-of' documentation, audience evaluations, and production diaries.

Students assembled a repository of visuals and continuously jotted down their reflections. 'While I am writing this short reflection on how I'm learning about visual methods, I'm also very aware of how my own frame of mind/looking determines my interpretation of these two images.' The shortest version of learning and reflection is the student statement: 'I cannot even watch a silly Netflix series at the moment without thinking about the making' (VRM student reports).

\section{Designing diversity sensitive learning}

Learning is about creating a space for learning and designing appropriate learning strategies and materials within that space (Lie and Witteveen, 2013). Learning in diversity means that the learning strategy and activities are deliberately designed to make use of cultural diversity in one way or the other. Learning in a cultural diversity sensitive way has been explicitly considered in the three selected courses, as the design addressed cultural diversity as embodied in student groups, and in the methods and knowledges with deliberate contributions to the learning space. The three courses reveal various aspects of diversity sensitive learning including aspects of learning in diversity, about diversity, and aiming to learn from diversity. From the courses we can now address diversity in a learning space at three domains: people, content, and process. Focusing here on the learning design of courses does not give many options to address how diversity sensitive learning is a systemic aspect of the educational institution. We will address this wider setting later.

Based on identifying parallels between the courses, the next sections elaborate on underlying principles. We thereby follow the distinction made between people, content, and process to indicate aspects of diversity sensitive learning. Following this distinction, we identify three design principles. These principles are not mutually exclusive but overlap and complement each other. We will, under each principle, describe a specific parallel, which emerged from the analyses of the courses. After that, we reflect on the principle so that it becomes of relevance to learning design at course level at universities as well as to other institutional levels aiming to design learning in a culturally and diversity sensitive way.

\section{Principle 1: Situating knowledges}

In terms of content, the three courses showed parallels in learning about diversity of knowledges. For example, the course Intercultural Communication addressed theories of globalisation, cultural mixing, acculturation, and identity construction, which students then apply to their field of expertise. In the course African Philosophy, students learned about perspectives and reasoning of African 
philosophers, which are less known to many students. The Visual Research Methods course built almost literally on different views focussing on theories and models for visual analysis. These courses emphasised the reinterpretation and re-construction of knowledges as central processes in learning and diversity.

Knowledges are situated in the sense that they are embedded in pre-existing situations, which also influence the design of the learning system. These knowledges are operational as epistemic and procedural lenses in the learning system (Kenter et al., 2019) as they interact with each other and create synergy or conflict between the learners, and as they react to the underlying values in the learning design and thereby influence the learning process. Such a perspective on learning experiences in the classroom has consequences for the imperatives of perspectives on learning. Looking through a lens of diversity sensitive learning is about recognising the complete epistemological context of selected knowledges and the designed learning strategies, and not only about bringing diverse knowledges on stage. Therefore, the learning situation is conceptualised as a space where different cultural embedded knowledges meet and are explicitly challenged to reach an articulated hybridisation of a diversity of knowledges and learning outcomes. The essential point is that knowledge and learning are not neutral or objective but that — as Paulo Freire (1970) remarked years ago-knowledge is political. This point is in line Banks et al.'s (2001) 12 principles on education for policymakers and practitioners aiming for appropriate educational practices in a multicultural societies; namely, that 'students understand that knowledge is socially constructed' (Banks et al., 2001, p. 198).

\section{Principle 2: Enabling dialogical encounters}

In terms of process, the three courses share the need for what we have termed enabling dialogical encounters, which emphasises engaging in dialogical encounters with 'the Other.' Although the African Philosophy course did not create direct dialogical encounters between students and philosophers, students practised with the methodology of listening to each other-an essential first step of such an encounter. In this same line, students in Intercultural Communication were engaged in dialogues with each other about different intercultural experiences and theories. Students in the Visual Research Methods course work in groups and are exposed to mediated encounters with diverse people and communities during the assignments.

Each of the three courses explicitly paid attention to how 'the Other' is represented and approached within a dominant Western perspective. For example, the course Intercultural Communication used a museum assignment in which students made a semiotic analysis of 'the Other,' which led to discussions among students about different interpretations of this representation. The Visual Research Methods course included a visual analysis of media outings and (cultural) diversity. In the same course, students analysed the production stages of a short film, which provided a system view on the continuity of 'Orientalism' and 'othering.' 
Practising to reverse 'othering' by changing positions in a cultural system underlines 'otherness' as a relational concept, thereby addressing roles and accountability of all actors involved. In the African Philosophy course, students learned how in Hegel's Eurocentric concept of philosophy, Africans were portrayed as 'Others without philosophy.' Thus - although differently approached-all three courses deconstruct how 'the Other' is portrayed, represented, and framed. As such, all three courses contained crucial aspects of what we like to call 'Looking through a lens of diversity sensitive learning.' Awareness is created among students about dominant (Western) world views, which enables them to move beyond stereotypes and open up to other types of knowledge and ways of knowing.

Bringing this learning further, it will be challenging to practically engage in dialogue with distant others. However, ample opportunities exist to practice with dialogues among students themselves; a practice to establish human relations with others. Nevertheless, we remark how options for dialogue should explicitly take into account design principles to explore if or how dialogical encounters with 'the Other' can be created, for example, by creating online encounters with people who are geographically far away from the university.

In terms of people and process, it is essential to mention that diversity sensitive learning does not seek to create a homogenous group out of this diversity, but instead to offer a safe learning environment where diversity can be explored. The underlying idea is that there is a difference between people and cultures, while at the same time there is equality (Kimmerle, 2012). The relation 'equal, but different' may sound contradictory to some (Kimmerle, 2011) because our world is characterised by many unequal (power) relations between men and women, Western and 'non-Western' cultures, and students and teachers, among others. Such inequalities are founded on hierarchical thinking of 'superiority' of one group towards 'inferiority' of 'the other,' which is not conducive for diversity. The point is not to ignore existing inequalities, but instead, to insist on how equality entails that 'the ontological equality of all human beings ought to be realised in practice' (Ramose, 2020, p. 303).

From this it follows that in learning processes it is central to enhance the realisation that 'the other' is a human being. Although this may sound obvious, it is not as straightforward as it may seem. History shows-for example, in Western colonisation and in the current BLM protests - that to date there is a 'stubborn refusal to treat "the other" as a human being' (Ramose, 2020, p. 303). As the Ubuntu maxim umuntu ngumuntu nga bantu says, 'to be a human being is to affirm one's humanity by recognising the humanity of others and, on that basis, establish humane relations with them' (Ramose, 1999, p. 37).

Ramose pleads for a process of 're-humanisation of all human relationships' in which we learn to be human. How can we incorporate such a learning process in the design of intercultural education? Following Ramose (forthcoming) and Kimmerle (2011, 2012), we need an intercultural dialogical approach. A basic premise is the methodology of listening in which the listener takes the position that 'the others tell me something, which I could not have told myself by any 
means' (2012). It means that there is a willingness and openness to try and understand the other, even if this may not happen (Kimmerle, 2012).

\section{Principle 3: Integrating experience and reflection}

All three courses showed that 'integrating experience and reflection' are important aspects of diversity sensitive learning. For example, in Intercultural Communication students wrote an essay about a specific intercultural experience they went through, and they used theories from the course to critically describe and reflect on this experience. In the African Philosophy course, students reflected critically on a livestock development project in Mozambique through which students identified Eurocentric thinking in international development. In Visual Research Methods, students were requested to write down their reflections throughout the course. The main aim of these exercises in each course was that students gain insight into the origins and presence of their assumptions, while also learning through and from their experiences. All started from the premise that learning is about integrating experiences and reflection and not only about gaining theoretical and cognitive knowledge.

This principle is grounded in general learning theories and is termed by us as 'Integrating experience and reflection.' The principle of Integrating experience and reflection has been identified in many cases as a principle that guides learning and certainly is of value when it comes to 'diversity sensitive learning.' Lie and Witteveen (2019) write about this principle:

[what] stands out is the centrality of experiences and reflexivity. Kolb's experiential learning and Mezirow's transformative learning have both emphasised the importance of experiences, and reflections and reflexivity is widely seen as an important condition for collaborative learning. Having many experiences is a strong asset in adult learning processes. Experience is the key word in experiential learning, and old and new experiences lead - by the act of reflecting - to learning. Learning can therefore be seen as an interactive play between experiences and reflections and between observations and interpretations. Reflexivity is to be seen as a condition for learning. (Lie and Witteveen, 2019, p. 14)

\section{Looking through a lens of diversity sensitive learning: conclusion and recommendations}

Empathy, respect, and authenticity are commonly acknowledged principles (e.g. WUR, 2020) that hardly anyone would oppose. Still, they seem to be grounded in a linear and oppositional perspective on communication and learning, based also on a paradigm of binary thinking and 'othering' of minority groups. In this same line, cultural diversity in education is too-often approached and operationalised as a 'tick-the-box' exercise-in numbers of 'diverse students and staff,' 
which are complemented with special services such as student counsellors and social events. However, thinking about learning and cultural diversity in Higher Education requires a paradigm-shift towards a systemic, inclusive perspective on designing educational activities.

We aim to contribute to this shift and argue that meaningful diversity sensitive learning requires specific design principles to prepare for contemporary learning spaces in a changing world. It thereby positions learning as a designed and situated space. Based on the empirical analyses of courses in different arenas of social sciences, the overarching principle emerges that meaningful diversity sensitive learning requires an integrative transformative educational approach that works on three domains simultaneously: content, people, and process. Diversity sensitive learning is thus about teaching in diversity (people) about diversity (content) and learning from diversity (process). More specifically, to enhance diversity sensitive learning in learning spaces, the following three design principles have been discerned:

- Situating knowledges. This is the most fundamental principle, when it comes to content. It recognises that the re-interpretation and the re-construction of a diversity of knowledges are central in learning processes.

- Enabling dialogical encounters. This principle emphasises that learning processes occur through dialogical interactions between people.

- Integrating experience and reflection. This principle identifies experience and reflexivity as essential conditions for collaborative learning.

In our view, the focus on process - the how-is essential, as it is within the process that diversity in people and content come together as reflected in the two principles 'enabling dialogical encounters' and 'integrating experience and reflection.' The analyses revealed that all three courses explicitly focus on processes, whereas in policy arenas and society at large it is often only diversity in people and content that is addressed. This is also the case in the National Action Plan for Greater Diversity and Inclusion in Higher Education (Ministry of Education, Culture and Science in the Netherlands, 2020) in which only people and content are considered, with process never explicitly referred to.

Our proposed integrative and transformative approach involves a specific perspective on inclusive education; that is, looking through a lens of diversity sensitive learning. Rather than focussing on empathy values and pampering-which reinforces 'otherness' - it is about re-positioning 'the cultural other' and paves the way for understanding and acting on a diversity of epistemologies and cultural practices, which allows 'being different.' Global communities can no longer be defined by ethnicity, and therefore knowledge institutes have to acknowledge contemporary societal diversity concerns and take their share in dealing with debates surrounding dissonant heritage, discrimination and exclusion, cultural appropriation, and the most recent activated concept of cancel-culture. This is an ongoing transformation process. All learning manifestations-ranging from 
courses to programmes - require a deliberately designed learning space and policy in which diversity is a fact to consider. Diversity is thus a systemic aspect of learning spaces and should be treated as such: one cannot add diversity simply as a supplementary aspect to education. Instead, it is an integral part of the learning space and the institutional setting in which it is embedded. Diversity is not context: it is text.

\section{References}

Bhambra, G. K., Gebrial, D., and Nişancıoğlu, K. (2018). Decolonising the University. London: Pluto Press.

Banks, J. A., Cookson, P., Gay, G., Hawley, W. D., Irvine, J. J., Nieto, S., ... Stephan, W. G. (2001). Diversity within unity: Essential principles for teaching and learning in a multicultural society. Phi Delta Kappan, 83(3), 196-203.

Boogaard, B. K. (2019). The relevance of connecting sustainable agricultural development with African philosophy. South African Journal of Philosophy, 38(3), 273-286.

Boogaard, B. K. (forthcoming). Epistemic injustice in agricultural development: critical reflections on a livestock development project in rural Mozambique. Knowledge Management for Development Journal.

Freire, P. (1970). Pedagogy of the Oppressed. 30th Anniversary Edition (2005). London: Continuum International Publishing Group.

Gilbert, J. (2016). Transforming science education for the Anthropocene-is it possible? Research in Science Education, 46(2), 187-201.

Hall, S., Evans, J., and Nixon, S. (eds.) (2013). Representation. 2nd edition, New York: Sage.

Kenter, J. O., Raymond, C. M., van Riper, C. J. et al. (2019). Loving the mess: Navigating diversity and conflict in social values for sustainability. Sustainability Science, 14(5), 1439-1461.

Kimmerle, H. (2011). Respect for the Other and the refounding of society: Practical aspects of intercultural philosophy. In: Oosterling, H. and Ziarek, E. P. (eds.). Intermedialities: Philosophy, Arts, Politics. Lanham: Lexington Books, 137-152.

Kimmerle, H. (2012). Dialogues as form of intercultural philosophy. Iranian Society of Intercultural Philosophy. http://isiph.ir/en/?p=27

Kimmerle, H. (2016). Hegel's Eurocentric concept of philosophy. Confluence, Journal of World Philosophies, (1), 99-117.

Lie, R. and Witteveen, L. (2013). Spaces of intercultural learning. In: Mertens, S. (ed.). Internationale Perspectieven op Journalistiek. Ghent: Academia Press, 19-34.

Lie, R. and Witteveen, L. (2019). ICTs for learning in the field of rural communication. In: Servaes, J. (ed.). Handbook of Communication for Development and Social Change. Dordrecht: Springer.

Ministry of Education, Culture and Science in the Netherlands (2020). National Action Plan for Greater Diversity and Inclusion. Den Haag: Ministry of Education, Culture and Science in the Netherlands.

Ramose, M. B. (1999). Ecology through Ubuntu. In: Ramose, M. B. (ed.). African Philosophy through Ubuntu. Harare: Mond Books, 105-110.

Ramose, M. B. (2019). A Philosophy without memory cannot abolish slavery: On Epistemic Justice in South Africa. In: Hull, G. (ed.). Debating African Philosophy. Perspectives on Identity, Decolonial Ethics and Comparative Philosophy. London: Routledge, 60-72. 
Ramose, M. B. (2020). Critique of Ramon Grosfoguel's 'The Epistemic Decolonial Turn'. Alternation Journal. Interdisciplinary Journal for the Study of the Arts and Humanities in Southern Africa, 27(1), 271-307.

Rose, G. (2016). Visual Methodologies. An Introduction to Researching with Visual Materials. 4th edition, New York: Sage.

Scholz, R. W. and Steiner, G. (2015). The real type and ideal type of transdisciplinary processes: Part I-Theoretical foundations. Sustainability Science, 10(4), 527-544.

Oruka, H. O. (1995). Ecophilosophy and the parental Earth ethics (on the complex web of being). In: Graness, A. and Kresse, K. (eds.) (1997). Sagacious Reasoning: Henry Odera Oruka in Memoriam, Bern: Peter Lang, 119-131.

Osland, J. S. (1995). The Adventure of Working Abroad: Hero Tales from the Global Frontier. San Francisco: Jossey-Bass.

Witteveen, L. and Lie, R. (2019). Visual communication and social change. In: Servaes, J. (ed.). Handbook of Communication for Development and Social Change. Dordrecht: Springer.

Witteveen, L. and Van Rijn, A. (2014). Updating Cocoa Stories [film]. Den Haag: Ministry of Economic Affairs, Directorate General Agro. https://www.youtube.com/watch? $\mathrm{v}=-\mathrm{tSsIOT} 4 \mathrm{OAc}$

WUR (2020). Guidelines for Working in Multicultural Settings. 'Quality Needs Diversity. Student Charter 2019-2020. Wageningen University and Research Centre. https:// www.wur.nl/en/Education-Programmes/Current-Students/student-charter-2019 $-2020 . h t m$ 